
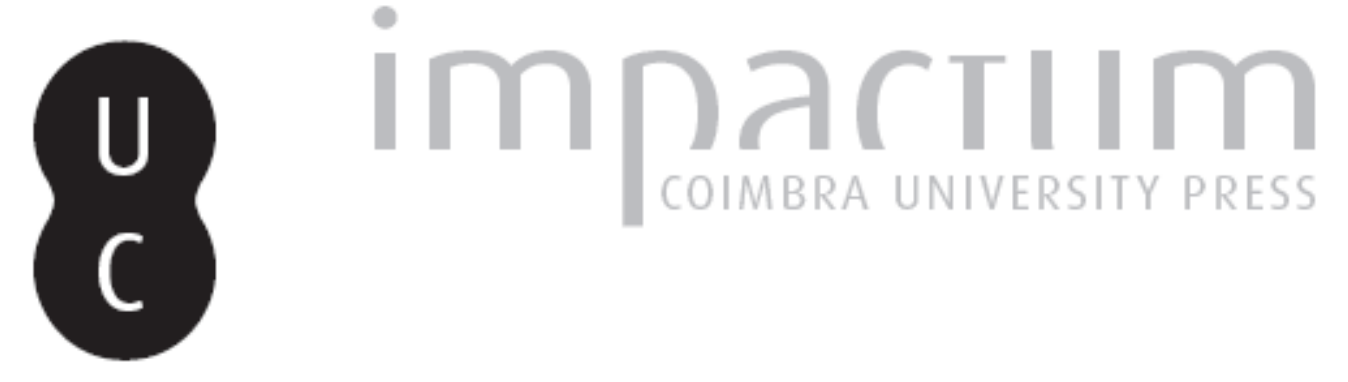

\title{
Pierre Hadot: reflexões sobre a noção de "cultura de si"
}

Autor(es): $\quad$ Stephan, Cassiana Lopes; Boganika, Luciane

Publicado por: Imprensa da Universidade de Coimbra, Instituto de Estudos Filosóficos

URL persistente:

URI:http://hdl.handle.net/10316.2/42152

DOI:

DOI:http://dx.doi.org/10.14195/0872-0851_51_8

Accessed : $\quad$ 26-Apr-2023 15:56:29

A navegação consulta e descarregamento dos títulos inseridos nas Bibliotecas Digitais UC Digitalis, UC Pombalina e UC Impactum, pressupõem a aceitação plena e sem reservas dos Termos e Condições de Uso destas Bibliotecas Digitais, disponíveis em https://digitalis.uc.pt/pt-pt/termos.

Conforme exposto nos referidos Termos e Condições de Uso, o descarregamento de títulos de acesso restrito requer uma licença válida de autorização devendo o utilizador aceder ao(s) documento(s) a partir de um endereço de IP da instituição detentora da supramencionada licença.

Ao utilizador é apenas permitido o descarregamento para uso pessoal, pelo que o emprego do(s) título(s) descarregado(s) para outro fim, designadamente comercial, carece de autorização do respetivo autor ou editor da obra.

Na medida em que todas as obras da UC Digitalis se encontram protegidas pelo Código do Direito de Autor e Direitos Conexos e demais legislação aplicável, toda a cópia, parcial ou total, deste documento, nos casos em que é legalmente admitida, deverá conter ou fazer-se acompanhar por este aviso.

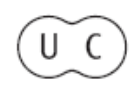




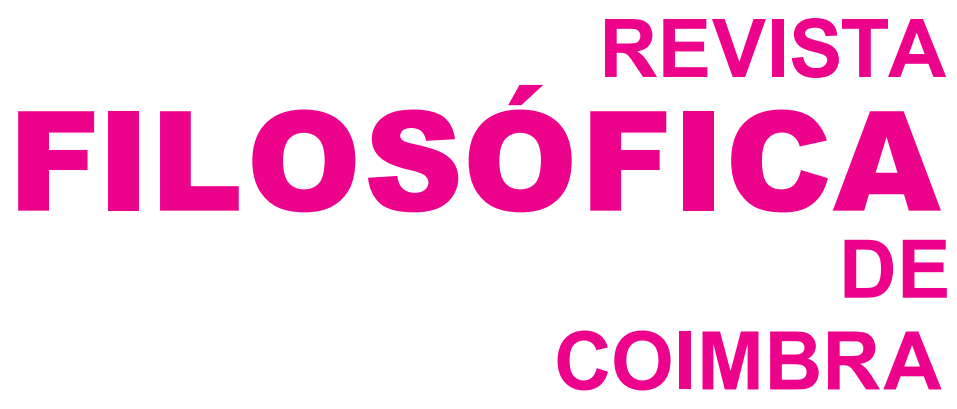

vol. 26 - número 51 - março 2017

vol. 26 - número 51 - março 2017

Fundação Eng. António de Almeida

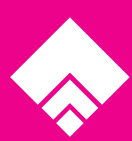




\section{PIERRE HADOT}

\section{REFLEXÕES SOBRE A NOÇÃO DE “CULTURA DE SI”}

Resumo: A presente tradução decorre do interesse em estudar os pormenores do diálogo entre Pierre Hadot e Michel Foucault no que concerne à Antiguidade filosófica. De fato, a comunicação "Reflexões sobre a noção de "cultura de si" " diz respeito ao texto que enseja e fundamenta o desenvolvimento desta pesquisa, iniciada no ano de 2013. Na ocasião, desconhecíamos a existência de uma tradução para o português da obra Exercices Spirituels et Philosophie Antique, na qual encontramos dois textos de Pierre Hadot explicitamente dedicados a Michel Foucault, a saber, "Un dialogue interrompu avec Michel Foucault: Convergences et Divergences" (Hadot, Exercices Spirituels, 1993, 305-311) e "Refléxions sur la notion de 'culture de soi"”. Estes textos foram elaborados após a prematura morte de Michel Foucault e neles Pierre Hadot pretendia dar continuidade a uma complexa conversa que se desencadeou no decorrer das investigações foucaultianas em relação às antigas asceses filosóficas, pois em diversas ocasiões Foucault se referiu aos estudos de Pierre Hadot sobre os exercícios espirituais (vd. A Hermenêutica do Sujeito, trad. de Márcio Alves da Fonseca e Salma Tannus Muchail, São Paulo: Martins Fontes, 2010, p. 194, p. 262, p. 347 e p. 375). Com efeito, optamos por traduzir apenas a comunicação "Refléxions sur la notion de "culture de soi" em virtude da riqueza filosófica e filológica que este texto apresenta, já que nele Pierre Hadot desenvolveu uma interessante articulação entre os principais autores do período helenístico-romano e as análises de Foucault acerca do cuidado de si [epiméleia heautoû], através da elaboração de duas críticas concernentes ao modo pelo qual Foucault interpretou a terapia das paixões [therapeuein] e a ultrapassagem de si [megalopsychia] na filosofia estoica. O livro Exercices Spirituels et Philosophie Antique foi primeiramente publicado em 1981 e reeditado em 1987. A edição utilizada nesta pesquisa corresponde ao ano de 1993, a qual foi revisada e aumentada através do acréscimo de algumas entrevistas, comu-

* Tradução e notas de Cassiana Lopes Stephan e Luciane Boganika.

Cedência dos direitos para efeitos de divulgação do excerto por parte da Editora Cavalo de Ferro. 
nicações e artigos de Pierre Hadot, entre eles aqueles dedicados a Michel Foucault. $\mathrm{O}$ trabalho de tradução se sucedeu em consonância à elaboração de notas nas quais indicamos os excertos referenciados por Pierre Hadot no decorrer desta importante comunicação, apresentada em um encontro internacional sobre a filosofia de Michel Foucault no ano de 1988. Ademais, tendo em vista a recente publicação da edição brasileira da obra Exercícios Espirituais e Filosofia Antiga, apontamos e discutimos as diferenças de opção no que concerne a nossa versão e à tradução de Flavio Fontenelle Loque e Loraine Oliveira (Exercícios Espirituais e Filosofia Antiga, São Paulo: É Realizações, 2014, pp. 291-300).

\begin{abstract}
The following translation, Reflections on the idea of the "Cultivation of the self", stems from the interest in studying the details of the dialogue between Pierre Hadot and Michel Foucault regarding their own theoretical interests with respect to Ancient philosophy. In fact, the communication "Reflexões sobre a noção de 'cultura de si"" [Reflections on the idea of the "Cultivation of the self"] refers to the text that inspires and justifies the development of this research, which began in 2013. At that time, we ignored the existence of a translation into Portuguese of the work Exercices Spirituels et Philosophie Antique [Spiritual Exercises and Ancient Philosophy], in which we find two Pierre Hadot's texts explicitly dedicated to Michel Foucault, namely "Un dialogue interrompu avec Michel Foucault: Convergences et Divergences" [An interrupted dialogue with Michel Foucault: Convergences and Divergences] (Hadot, Exercices Spirituels 1993, 305-311) and "Refléxions sur la notion de "culture de soi"" [Reflections on the idea of the "Cultivation of the self"]. These texts were drawn up after the premature death of Michel Foucault and in them Pierre Hadot intended to continue
\end{abstract}

Résumé: Cette traduction, Réflexions sur la notion de "culture de soi», naît de l'intérêt d'étudier les détails du dialogue entre Pierre Hadot et Michel Foucault sur 1'Antiquité philosophique. En effet, l'article intitulé Réflexions sur la notion de "culture de soi » se réfère au texte qui fait éclore et étaie le développement de cette recherche commencée en 2013. À l'époque, nous n'avions pas connaissance de l'existence d'une traduction en portugais de l'œuvre Exercices Spirituels et Philosophie Antique, dans laquelle se trouvent deux textes de Pierre Hadot explicitement consacrés à Michel Foucault, à savoir, Un dialogue interrompu avec Michel Foucault. Convergences et divergences, (Hadot, Exercices Spirituels, 1993, pp. 305-311) et Réflexions sur la notion de "culture de soi ». Ces textes ont été rédigés après la mort prématurée de Michel Foucault ; Pierre Hadot cherchait à donner une continuité à une conversation complexe qu'il a développée au cours de les recherches de Foucault sur les antiques ascèses philosophiques. À de nombreuses reprises, Foucault a en effet fait référence aux études de Pierre Hadot sur les exercices spirituels (vd. A Hermenêutica do Sujeito, trad. de M. A. da Fonseca e S. 
a complex conversation that was unleashed in the course of Foucault's researches about Ancient philosophical asceticism. In several occasions, Foucault referred his own investigations to Pierre Hadot' studies on spiritual exercises (vd.A Hermenêutica do Sujeito, trad. de M. A. da Fonseca e S. T. Muchail, São Paulo: Martins Fontes, 2010, p. 194, p. 262, p. 347 and p. 375). Indeed, we have chosen to translate only the communication named "Refléxions sur la notion de "culture de soi" [Reflections on the idea of the "Cultivation of the self"] due to its philosophical and philological richness. Pierre Hadot developed in it an interesting relationship between main authors of the Hellenistic and Roman periods and Foucault's analysis concerning the care of the self [epimeleia heautou], through the elaboration of two criticisms regarding the way Foucault interpreted the therapy of passions [therapeuein] and the surpassing of the self [megalopsychia] in Stoic philosophy. The book Exercices Spirituels et Philosophie Antique [Spiritual Exercises and Ancient Philosophy] was first published in 1981 and reissued in 1987. The edition used in this study corresponds to the year of 1993. This version was revised and increased with the addition of some interviews, communications and some of Pierre Hadot's papers, including those dedicated to Michel Foucault. The translation work has been elaborated in accordance with the preparation of notes in which we indicate the excerpts referenced by Pierre Hadot during this important communication, presented at an international meeting on Michel Foucault's philosophy, in 1988.
T. Muchail, São Paulo: Martins Fontes, 2010 , p. 194 , p. 262 , p. 347 et p. 375 ). Dès lors, nous avons choisi de traduire uniquement l'article Réflexions sur la notion de «culture de soi » en raison de la richesse de la pensée philosophique et philologique que ce texte présente : Pierre Hadot y développe une relation intéressante entre les principaux auteurs de la période gréco-romaine et les analyses de Foucault sur le souci de soi [epiméleia heautoû], à travers l'élaboration de deux critiques concernant le mode par lequel Foucault a interprété la thérapie des passions [therapeuein] et la grandeur d'âme [megalopsychia] dans la philosophie stoïcienne. Le livre Exercices Spirituels et Philosophie Antique a d'abord été publié en 1981 puis réédité en 1987. L'édition utilisée dans cette recherche correspond à celle de 1993, révisée et augmentée avec des entretiens, des interventions et des articles de Pierre Hadot, dont certains consacrés à Michel Foucault. Le travail de traduction a été réalisé à l'aide de notes dans lesquelles nous indiquons les extraits référencés par Pierre Hadot dans le cadre de cet important article présenté lors d'une réunion internationale sur la philosophie de Michel Foucault en 1988. En outre, en raison de la récente publication de l'édition brésilienne des Exercices Spirituels et Philosophie Antique, nous présentons et discutons les différences de traitement dans notre version et dans la traduction de Flavio Fontenelle Loque et Loraine Oliveira (Exercícios Espirituais e Filosofia Antiga, São Paulo: É Realizações, 2014, pp. 291-300). 
Furthermore, in view of the recent publication of the Brazilian edition of the book Exercícios Espirituais e Filosofia Antiga, we point out and discuss different options concerning our version and the mentioned translation developed by Flavio Fontenelle Loque and Loraine Oliveira (Exercicios Espirituais e Filosofia Antiga, São Paulo: É Realizações, 2014, pp. 291-300).

$* * *$

\section{Reflexões sobre a noção de "cultura de si"**}

M. Foucault evocou, no prefácio de $O$ uso dos prazeres ${ }^{1}$ e em um capítulo do Cuidado de $s i^{2}$, meu artigo "Exercícios espirituais" [Exercices spirituels], publicado no Annuaire de la Ve Section de l'École Pratique des Hautes Études, nos anos de 1975-1976, e reproduzido em meu livro Exercícios Espirituais e Filosofia Antiga que, publicado em 1981, acaba de ser reeditado em 1987. A descrição que eu dava, neste artigo, da filosofia antiga como arte de viver, como estilo de vida, como maneira de vida, o esforço que eu fazia também, neste estudo, para explicar porque a filosofia moderna esquecera esta tradição e tornara-se quase exclusivamente um discurso teórico, a ideia que delineava, e que em seguida desenvolvi no meu livro Exercícios espirituais, a ideia segundo a qual o cristianismo recuperou, à sua maneira, certas técnicas dos exercícios espirituais praticados na Antiguidade, tudo isto, parece-me, reteve a atenção de M. Foucault. ${ }^{3}$

Gostaria de apresentar aqui certas observações destinadas a especificar, para além desta convergência, as diferenças de interpretação e, finalmente, de opção filosófica que nos separavam e que teriam podido alimentar um diálogo que, infelizmente, a morte prematura de M. Foucault rapidamente interrompeu.

M. Foucault descreve com precisão, em $O$ Cuidado de si, o que ele chama de "práticas de si" sustentadas pelos filósofos estoicos na Antiguidade: o cuidado de si mesmo, o qual, por sinal, só pode ser realizado sob a direção de

* Pierre Hadot, "Réflexions sur la notion de 'culture de soi"”, in: Exercices spirituels et philosophie antique (Paris: Albin Michel, 1993), 323-332. 
um guia espiritual, a atenção ao corpo e à alma que implica este cuidado de si mesmo, os exercícios de abstinência, o exame de consciência, a filtragem das representações e finalmente a conversão em direção a si, a posse de si. M. Foucault concebe estas práticas como "artes da existência" e "técnicas de si". E é bem verdade que, na Antiguidade, falava-se a respeito da "arte de viver". Mas, parece-me que a descrição que $\mathrm{M}$. Foucault dá àquilo que eu nomeara "exercícios espirituais", e que ele prefere chamar de "técnicas de si", está demasiadamente centrada no "si", ou, ao menos, sobre certa concepção de si. ${ }^{4}$

Notavelmente, Foucault apresenta a ética do mundo greco-romano como uma ética do prazer que se obtém em si mesmo: "A essa espécie de prazeres violentos, incertos e provisórios, o acesso a si é suscetível de substituir uma forma de prazer que, na serenidade e para sempre, se tem consigo mesmo." 5 E ele cita, para ilustrar sua proposta, a Carta XXIII de Sêneca na qual está em questão a alegria que se encontra em si mesmo, exatamente na melhor parte de si mesmo. ${ }^{6}$ Mas, de fato, devo dizer que existe muita inexatidão nesta apresentação das coisas. Na carta XXIII, Sêneca opõe explicitamente voluptas e gaudium, o prazer e a alegria, então, não se pode falar acerca da alegria, do mesmo modo que faz Foucault, como uma "outra forma de prazer."7 Não se refere somente a uma questão de palavras, embora os estoicos tenham atribuído uma grande importância a elas e tenham distinguido cuidadosamente entre hèdonè e eupathéia, precisamente entre o prazer e a alegria (reencontraremos a diferença em Plotino ${ }^{8}$ e em Bergson, este último vinculando a alegria à criação ${ }^{9}$ ). Não, não se trata somente de uma questão de vocabulário: se os estoicos mantêm a palavra gaudium, a palavra "alegria", é precisamente porque eles recusam introduzir o princípio do prazer na vida moral. A felicidade para eles não consiste no prazer, mas na virtude em si, a qual é por si mesma sua própria recompensa. Bem antes de $\mathrm{Kant}^{10}$, os estoicos quiseram preservar zelosamente a pureza da intenção da consciência moral. ${ }^{11}$

Em segundo lugar e, sobretudo, o estoico não encontra sua alegria no seu "eu", mas, diz Sêneca, "na melhor parte de si", no "bem verdadeiro"12, isto é, "na consciência voltada em direção ao bem, nas intenções que não têm outro objeto a não ser a virtude, as ações retas" 13 , ou seja, naquilo que Sêneca chama de razão perfeita ${ }^{14}$, ou ainda finalmente na razão divina ${ }^{15}$, já que, para ele, a razão humana nada mais é do que uma razão perfectível. A "melhor parte" de si é então, finalmente, um si transcendente. ${ }^{16}$ Sêneca não encontra sua alegria em Sêneca, mas transcendendo Sêneca, descobrindo que ele tem em si uma razão, parte da Razão universal, interna a todos os homens e ao cosmos em si mesmo.

O exercício estoico visa, de fato, a ultrapassar o si, a pensar e a agir em união com a Razão universal. ${ }^{17}$ Os três exercícios descritos por Marco $\mathrm{Au}$ rélio, na esteira de Epicteto $^{18}$, são muito significativos no que diz respeito a 
isso: julgar de uma maneira objetiva de acordo com a razão interior ${ }^{19}$, agir de acordo com a razão que é comum a todos os homens ${ }^{20}$, aceitar o destino que nos é imposto pela razão cósmica. ${ }^{21}$ Para os estoicos, há somente uma única razão e essa razão é o verdadeiro si do homem. ${ }^{22}$

Eu compreendo perfeitamente o motivo pelo qual Foucault suprimiu esses aspectos, os quais ele conhecia bem. Sua descrição das práticas de si (como, ademais, minha descrição dos exercícios espirituais) não concerne somente a um estudo histórico, mas quer implicitamente oferecer ao homem contemporâneo um modelo de vida (que Foucault chama de "estética da existência"). Ora, segundo uma tendência quase geral do pensamento moderno, tendência talvez mais instintiva do que refletida, as noções de "Razão Universal" e de "natureza universal" não têm mais hodiernamente muito sentido. Era, portanto, útil colocá-las entre parênteses.

Para o momento, digamos, portanto, que parece difícil, de um ponto de vista histórico, admitir que a prática filosófica dos estoicos e dos platônicos tenha sido somente uma relação a si, uma cultura de si, um prazer obtido em si mesmo. O conteúdo psíquico desses exercícios me parece totalmente outro. O sentimento de pertença a um Todo me parece ser o elemento essencial: pertença ao Todo da comunidade humana, pertença ao Todo cósmico. Sêneca resume isso em quatro palavras: "Toti se inserens mundo" ("mergulhando na totalidade do mundo"). ${ }^{23}$ Groethuysen, em sua admirável Antropologia Filosófica [Anthropologie philosophique], reconheceu muito bem esse traço fundamental. ${ }^{24}$ Ora, uma tal perspectiva cósmica transforma de uma maneira radical o sentimento que se pode ter de si mesmo.

Curiosamente, Foucault fala pouco dos epicuristas. Isso é particularmente muito inesperado, pois em certo sentido a ética epicurista é uma ética sem norma, uma ética autônoma que não pode se fundar sobre a Natureza, produto do acaso, uma ética, portanto, que pareceria concordar perfeitamente com a mentalidade moderna. A razão desse silêncio se encontra talvez no fato de que é muito difícil integrar o hedonismo epicurista ao esquema geral do uso dos prazeres proposto por M. Foucault. Seja como for, também existem práticas espirituais para os epicuristas, por exemplo, o exame de consciência. Mas, como nós dissemos, estas práticas não se fundam sobre as normas da Natureza e da Razão universal, visto que, para os epicuristas, a formação do mundo é somente o resultado do acaso. E, entretanto, aqui ainda, essa prática espiritual não pode se definir apenas como uma cultura de si, como uma simples relação de si a si, como um prazer que se encontraria em seu próprio eu. $\mathrm{O}$ epicurista não tem medo de confessar que necessita de algo para além de si mesmo para satisfazer seus desejos e encontrar seu prazer: a ele é necessário o alimento corporal, os prazeres do amor, mas também uma teoria física do universo para suprimir o medo dos deuses e da morte. A ele é necessário o convívio com os outros membros da escola epicurista para encontrar 
a felicidade na afeição mútua. Por fim, a ele é necessária a contemplação imaginativa da infinidade de universos no vazio infinito para experimentar isso que Lucrécio chama divina voluptas et horror. ${ }^{25}$ Essa imersão do sábio epicurista no cosmos é bem expressa pelo discípulo de Epicuro, Metrodoro: "Recorda-te de que, ainda que sejas de natureza mortal e com um limite finito de vida, te debruçaste, mediante a investigação da natureza, no que é infinito e eterno, e comtemplaste o que é agora, será e sempre foi no tempo transcorrido." 26 Há, no epicurismo, uma extraordinária inversão de perspectiva: precisamente porque a existência aparece ao epicurista como um puro acaso, inexoravelmente único, ele acolhe a vida como um tipo de milagre, como um dom gratuito e inesperado da Natureza e ele considera a existência como uma festa maravilhosa.

Eu tomarei agora outro exemplo para ilustrar a diferença de nossas interpretações acerca do "cuidado de si". M. Foucault escreveu um interessante artigo intitulado "Escrita de si" que toma, ademais, como ponto de partida uma notável obra concernente ao valor terapêutico da escrita ${ }^{27}$, o qual eu havia estudado em meus Exercícios Espirituais, ${ }^{28}$ nessa obra, o célebre monge Antônio aconselhara seus discípulos a anotar por escrito as ações e os movimentos de suas almas, como se eles tivessem que torná-los conhecidos aos outros: "Que a escrita mantenha, então, o lugar do olho de outrem", dizia Antônio. ${ }^{29}$ Essa anedota leva M. Foucault a refletir sobre as formas que haviam tomado isso que ele designa como "escrita de si" na Antiguidade e, notavelmente, sobre o gênero literário dos hypomnèmata, o que se poderia chamar de "cadernos de notas" espirituais, onde se registram os pensamentos de outrem, os quais podem servir à própria edificação daquele que os escreve. Foucault define assim o propósito dos cadernos: consiste em "captar o já-dito", em "reunir o que se pôde ouvir ou ler, isso por um fim que nada mais é do que a constituição de si" ${ }^{30}$. Em seguida, ele se pergunta: "Como ser colocado em presença de si mesmo através do auxílio de discursos antigos e provenientes de toda parte?"31 E eis aqui sua resposta: "Esse exercício permitiria retornar ao passado: a contribuição dos hypomnèmata é um dos meios pelos quais se afasta a alma da preocupação com o futuro para incliná-la à meditação do passado." 32 Ele acredita detectar, tanto na moral epicurista quanto na moral estoica, a recusa de uma atitude de espírito voltada ao futuro e a tendência a atribuir um valor positivo à posse de um passado de que se pode desfrutar soberanamente e sem perturbação. Parece-me que há aqui um erro de interpretação. É verdade que os epicuristas, mas somente eles, consideram como uma das fontes principais do prazer a lembrança dos momentos agradáveis do passado, contudo, isso não tem nada a ver com a meditação do "já-dito" praticada nos hypomnèmata. No entanto, não deixa de ser verdadeiro, como eu mostrei em um artigo publicado na Diogène em 1986 ( $\left.{ }^{\circ} 133\right)$, que estoicos e epicuristas concordam em uma 
atitude que consiste em liberar-se tanto da preocupação com o futuro quanto do peso do passado para se concentrar sobre o momento presente, seja para desfrutá-lo, seja para nele agir. ${ }^{33} \mathrm{E}$, desse ponto de vista, nem os estoicos e nem mesmo os epicuristas atribuíram um valor positivo ao passado: a atitude filosófica fundamental consiste em viver o presente, em possuir o presente e não o passado. Que eles tenham, ademais, vinculado muita importância aos pensamentos formulados pelos seus predecessores, concerne à outra coisa. Porém, se os hypomnèmata incidem sobre o já-dito, não é sobre qualquer "já-dito", que teria simplesmente o mérito de ser do passado, mas é porque se reconhece nesse já-dito (em geral, os dogmas dos fundadores da escola) isso que a própria razão diz no presente, é porque se reconhece, nesses dogmas de Epicuro ou Crisipo, um valor sempre presente, pois, precisamente, eles são a expressão mesma da razão. Dito de outro modo, ao escrever, ao anotar, não se faz seu um pensamento alheio, mas utilizam-se fórmulas que são consideradas bem feitas para atualizar, para tornar vivo, isso que já está presente no interior da razão daquele que escreve.

Esse exercício, segundo M. Foucault, se pretenderia voluntariamente eclético, e, portanto, implicaria uma escolha pessoal, o que explicaria assim a "constituição de si". 34 "A escrita como exercício pessoal feito para si e por si é uma arte da verdade díspar ou mais precisamente uma maneira reflexiva de combinar a autoridade tradicional da coisa já dita com a singularidade da verdade que se afirma e a particularidade das circunstâncias que determinam seu uso." 35 Mas, de fato, ao menos para os estoicos e para os epicuristas, não é no ecletismo que se dá a escolha pessoal. ${ }^{36} \mathrm{O}$ ecletismo é utilizado somente quando se trata de converter os iniciantes. Neste momento, todos os meios são bons. Assim, Foucault encontra um exemplo de ecletismo nas Cartas a Lucílio, nas quais Sêneca, o estoico, cita sentenças de Epicuro. Mas, trata-se de converter Lucílio, de fazer com que ele comece a praticar uma vida moral. Essa utilização de Epicuro aparece somente nas primeiras Cartas e desaparece rapidamente. De fato, a escolha pessoal se encontra, ao contrário, na adesão exclusiva a uma forma de vida precisa, estoicismo ou epicurismo, considerada conforme à razão. É somente na nova Academia, com Cícero, por exemplo, que a escolha pessoal se faz segundo o que a razão considera como provável a tal ou tal momento. ${ }^{37}$

Portanto não é, como pensa Foucault, escrevendo e relendo os pensamentos díspares que o indivíduo se forja uma identidade espiritual. ${ }^{38}$ Primeiramente, nós vimos, estes pensamentos não são díspares, mas escolhidos por sua coerência. Em segundo lugar e, sobretudo, não se trata de se forjar uma identidade espiritual escrevendo, mas de se liberar de sua individualidade para se elevar à universalidade. Portanto, é inexato falar em "escrita de si"; não somente não se escreve si mesmo, como a escrita não constitui o si: ${ }^{39}$ do mesmo modo que os outros exercícios espirituais, ela faz com que o eu mude 
de nível, ela o universaliza. O milagre desse exercício, praticado na solidão, é que ele permite aceder à universalidade da razão no tempo e no espaço. Para o monge Antônio, o valor terapêutico da escrita consiste precisamente neste poder universalizante. A escrita, diz Antônio, ocupa o lugar do olho do outro. Aquele que escreve se sente, de alguma maneira, olhado, ele não está mais sozinho, mas é parte da comunidade humana presente silenciosamente. Ao formular por escrito seus atos pessoais, se é tomado pela engrenagem da razão, da lógica, da universalidade. Objetiva-se aquilo que era confuso e subjetivo.

Em suma, o que Foucault chama de "práticas de si" de acordo com os estoicos, e também com os platônicos, corresponde bem, e isto é verdade, a um movimento de conversão em direção a si: libera-se da exterioridade, do apego passional aos objetos exteriores e aos prazeres que eles podem propiciar, observa-se a si mesmo para ver se se progrediu neste exercício, procura-se ser mestre de si mesmo, possuir a si mesmo, encontrar sua felicidade na liberdade e na independência interior. Eu estou de acordo com todos estes pontos. Contudo, penso que este movimento de interiorização é inseparavelmente solidário a outro movimento, no qual se eleva a um nível psíquico superior em que se encontra um outro tipo de exteriorização, uma outra relação ao exterior, uma nova maneira de estar-no-mundo e que consiste em tomar consciência de si como parte da Natureza, como parcela da Razão universal. Não se vive mais no mundo humano convencional e habitual, mas no mundo da Natureza. Como eu já disse em outro momento, pratica-se, dessa maneira, a "física" como exercício espiritual. ${ }^{40}$

Identifica-se, assim, a um "outro", que é a Natureza, a Razão Universal, presente em cada indivíduo. Há, no indivíduo, uma transformação radical das perspectivas, uma dimensão universalista e cósmica sobre a qual $\mathrm{M}$. Foucault, parece-me, não insistiu suficientemente: a interiorização é ultrapassagem de si e universalização. ${ }^{41}$

Todas as observações que eu acabo de desenvolver não se situam somente no quadro de uma análise histórica da filosofia antiga, elas visam igualmente à definição do modelo ético que o homem moderno pode descobrir na Antiguidade. E, precisamente, temo um pouco que, centrando exclusivamente sua interpretação sobre a cultura de si, sobre o cuidado de si, sobre a conversão a si e, de uma maneira geral, definindo seu modelo ético como uma estética da existência, M. Foucault proponha uma cultura de si puramente estética, isto é, eu temo uma nova forma de dandismo versão de fim do século $20 .^{42}$ Porém, isto deveria ser estudado com mais atenção do que eu posso fazê-lo. De minha parte, eu creio sem hesitação, e talvez ingenuamente, na possibilidade, para o homem moderno, de viver, não a sabedoria (os Antigos, em sua maioria, não acreditavam nessa possibilidade), mas um exercício, sempre frágil, da sabedoria na tripla forma que definia, nós o vimos, Marco 
Aurélio: esforço para praticar a objetividade do julgamento, esforço para viver segundo a justiça e ao serviço da comunidade humana, esforço para tomar consciência da nossa situação de parte no universo (exercendo-se a partir da experiência vivida do sujeito concreto, vivente e percipiente). Então, esse exercício da sabedoria será um esforço para se abrir ao universal.

Mais precisamente ainda, eu penso que o homem moderno pode praticar os exercícios filosóficos da Antiguidade, separando-os do discurso filosófico ou místico que os acompanhava. Pode-se seguramente justificar o mesmo exercício espiritual com discursos filosóficos extremamente diferentes, que são somente tentativas desajeitadas, que vêm posteriormente, de descrever e justificar experiências interiores cuja densidade existencial escapa, finalmente, a todo esforço de teorização e sistematização. Por exemplo, os estoicos e os epicuristas convidaram seus discípulos, por razões totalmente diferentes, a concentrar a sua atenção sobre o momento presente, liberando-se da preocupação com o futuro e do peso do passado. Mas aquele que pratica concretamente este exercício vê o universo com novos olhos, como se ele o visse pela primeira vez, ele descobre, no desfrute do presente puro, o mistério e o esplendor da existência; e, como falava Nietzsche, nós dizemos, então, sim "não somente a nós mesmos, mas a toda existência." 43 Portanto, não é necessário acreditar na Natureza universal e na Razão universal dos estoicos para praticar estes exercícios, mas os praticando, vive-se concretamente segundo a razão ("se tudo acontece por acaso, não se deixe levar, você, ao acaso", dizia Marco Aurélio ${ }^{44}$ ), acede-se concretamente à universalidade da perspectiva cósmica, à presença maravilhosa e misteriosa do universo.

\section{Bibliografia**}

BERGSON, J. L'Énergie Spirituelle. 14.ed. Paris: PUF, 1930.

FOUCAULT, M. «L'Écriture de soi ». Corps Écrit, n5, 1983, p.3-23.

FOUCAULT, M. Histoire de la Sexualité. Paris: Gallimard, 1952. t. II, “L’Usage des Plaisirs"; t. III, "Le Souci de Soi".

GROETHUYSEN, B. Anthropologie Philosophique. Paris: Gallimard, 1952.

HADOT, I. « Épicure et l'Enseignement Philosophique Hellénestique et Romain », Actes du VIII Congrés de l'Association Guillaume Budé. Paris: Belles Lettres, 1970, p. 35.

** As obras aqui citadas correspondem as que são referenciadas pelo próprio Pierre Hadot ao termo de sua comunicação. (Hadot, Exercices Spirituels, 332) As peças bibliográficas articuladas no decorrer das investigações que transcorreram nossa tradução estão listadas no fim deste trabalho. 
HADOT, I. Seneca und die griechish-römische Tradition der Seelenleitung. Berlin, 1969.

HADOT, P. Exercices Spirituels et Philosophie Antique. 2.ed. Paris : Institut d'Études Augustiniennes, 1987.

HADOT, P. « Le Present Seul est Notre Bonheur. La Valeur de l'Instant Present chez Goethe et dans la Philosophie Antique ». Diogène, Paris, nº133, 1986, pp. 58-81.

SCHIMID, W. Die Geburt des Philopohie im Garten der Lüste, Frankfurt am main, Athenäum, 1987.

\section{Notas Críticas}

1 No prefácio ao "Uso dos Prazeres", Foucault explica que os livros de Pierre Hadot foram extremamente importantes para o desenvolvimento de suas investigações em relação à Antiguidade: "o perigo era também o de abordar documentos por mim mal conhecidos. Corria o risco de submetê-los, sem me dar conta, a formas de análise ou a modos de questionamento que, vindos de outros lugares, não lhes convinham; os livros de P. Brown, os de P. Hadot e, em várias ocasiões, seus pareceres e as conversações que mantivemos, me foram de grande valia." [Michel Foucault, A História da Sexualidade 2: O uso dos prazeres, trad. de Maria Thereza da Costa Albuquerque (São Paulo: Graal, 2012), 14]

2 Foucault faz referência ao livro de Hadot, Exercices Spirituels et Philosophie Antique, no capítulo "A cultura de si mesmo", do último volume da História da Sexualidade [Cf. Michel Foucault, A História da Sexualidade 3: O cuidado de si, trad. de Maria Thereza da Costa Albuquerque (São Paulo: Graal, 2011), 49, nota 3].

3 As obras de Hadot estudadas por Foucault correspondem ao livro Exercices Spirituels et Philosophie Antique, mas também ao artigo, apresentado em 1953 no Congresso de Filosofia de Bruxelas, no qual Hadot discute a noção de conversão, a saber, "Epistrophé et metanoia dans l'histoire de la philosophie". (Hadot, Exercices Spirituels, 305)

${ }^{4} \mathrm{Na}$ tradução para o português, desenvolvida por Flavio Fontenelle Loque e Loraine Oliveira, este trecho do texto de Pierre Hadot aparece da seguinte forma: "Parece-me, porém, que a descrição que M. Foucault realiza do que eu havia denominado 'exercícios espirituais', e que ele prefere chamar de 'técnicas de si', está demasiadamente centrada sobre o 'si' [soi] ou, ao menos, sobre certa concepção do eu [soi]." (Loque e Oliveira, Exercícios Espirituais, 292) Como é possível perceber, os autores traduzem indistintamente "soi" por "si" e por "eu", isto é, eles não tornam explícita a diferença de uso, tanto gramatical quanto histórico-filosófico, entre o pronome reflexivo da terceira pessoa (soi), o pronome reflexivo da primeira pessoa (moi) e o pronome pessoal (je). O mesmo acontece em outros momentos da tradução de Flavio e Loraine, por exemplo: ““A melhor parte de si’ é, portanto, finalmente, um eu [soi] transcendente'." (Loque e Oliveira, Exercícios Espirituais, 293) Por um lado, do ponto de vista gramatical, o termo em português que mais se aproxima ao francês "soi" consiste no "si", pronome reflexivo da terceira pessoa. Por outro lado, do ponto de vista histórico-filosófico, faz-se importante ressaltar a distinção entre esses termos em virtude da especificidade que a noção de "si" possui na Antiguidade. O "si" (soi) dos antigos exercícios de filosofia é muito diferente do "eu" (je-moi) unificado, completo e introspecto da modernidade filosófica. Em "L’individu dans la cité", Jean-Pierre Vernant classifica três formas de indivíduo que percor- 
rem a história da filosofia, dos antigos aos modernos. Vernant distingue entre o indivíduo, o sujeito e o eu. O indivíduo corresponde à experiência do "si" nos grupos dos quais faz parte, isto é, ao seu valor e papel nos diversos espaços sociais que ocupa. O sujeito diz respeito ao nível de individualidade que se manifesta quando o "si" fala, em seu próprio nome, sobre seu valor e papel nos diferentes enquadramentos comunitários dos quais participa. Por fim, a experiência de individualidade articulada ao eu corresponde ao nascimento da intimidade, da interioridade e da autenticidade de um "si" que deixa de se experimentar em relação ao mundo, e passa a experimentar o mundo em relação ao eu. Segundo Vernant, a Grécia clássica e helenística não teve a experiência da intimidade ou do "eu". Vernant compara esses três níveis de individualidade a gêneros literários: "o indivíduo corresponderia à biografia, no sentido em que, por oposição à narrativa épica ou histórica, a biografia se centra sobre a vida de uma personagem singular; ao sujeito corresponderia a autobiografia ou as Memórias quando o indivíduo conta, por si mesmo, sua própria carreira de vida; e ao eu corresponderiam as confissões e os diários íntimos, onde a vida interior, a pessoa singular do sujeito, na sua complexidade e sua riqueza psicológica, sua relativa incomunicabilidade, formam o conteúdo da escrita. Os gregos, a partir da época clássica, conheceram certas formas da biografia e da autobiografia. (...) não há, na Grécia clássica e helenística, nem as confissões e nem os diários íntimos - isso é impensável - como também, observava G. Minsch e o confirma A. Momigliano, a caracterização do indivíduo na autobiografia grega ignora a 'intimidade do eu'." [Jean-PierreVernant, "L'individu dans la cité", in: L'individu, la mort, l'amour: soi-même et l'autre en Grèce ancienne (Paris: Gallimard, 2011), 216] Ademais, para Foucault, a categoria de indivíduo é frequentemente invocada, em diferentes épocas, para explicar fenômenos bastante diversos: "de fato, convém distinguir três coisas: a atitude individualista, caracterizada pelo valor absoluto que se atribui ao indivíduo em sua singularidade e pelo grau de independência que lhe é atribuído em relação ao grupo ao qual ele pertence ou às instituições das quais ele depende; a valorização da vida privada, ou seja, a importância reconhecida às relações familiares, às formas de atividade doméstica e ao campo dos interesses patrimoniais; e, finalmente, a intensidade das relações consigo, isto é, das formas nas quais se é chamado a se tomar a si próprio como objeto de conhecimento e campo de ação para transformar-se, corrigir-se, purificar-se, e promover a própria salvação." (Foucault, A História da Sexualidade 3, 48) A partir dessas considerações, talvez seja possível afirmar, como explica Vernant, ao citar a fórmula de Groethuysen, que o "si" da antiguidade clássica e helenística apreende a si mesmo como um ele e não como um eu. (Vernant, "L'individu", 226-227) De acordo com Vernant, "a existência é primeira em relação à consciência de existir. Como comumente se nota, o cogito ergo sum, "eu penso logo existo', não tem nenhum sentido para um grego." [Vernant, "L'individu", 225; Cf. também Arnold Davidson, "Ethics as Ascetics: Foucault, the History of Ethics, and Ancient Thought", in: The Cambridge Companion to Foucault, ed. por Gary Gutting (Cambridge: Cambridge University Press, 2006), 134-137] Sendo assim, optamos por traduzir, em todos os momentos, o pronome "soi" por "si" e o pronome "je" ou o pronome "moi" por "eu".

5 Foucault, A História da Sexualidade 3, p.71.

6 "Só atinge o ponto supremo quem sabe em que consiste a verdadeira satisfação, quem não deixa a sua felicidade ao arbítrio dos outros. (...) O que tens a fazer antes de mais, caro Lucílio, é aprender a ser alegre (gaudere). Estás a pensar que eu te quero privar de muitos prazeres (voluptates) ao afastar de ti os bens fortuitos, ao entender que devemos subtrair-nos ao doce canto das sereias que é a esperança? Pelo contrário, o meu desejo é que nunca te falte alegria (laetitiam).” [Séneca, Cartas a Lucílio, trad. De J.A. Segurado e Campos (Lisboa: 
Calouste Gulbenkian, 2004), Carta 23, 84; Seneca, Annaei Senecae ad Lucilium Epistulae Morales, ed. por L. D. Reynolds (Oxford: Oxford University Press, 1965), Ep.23, §2 e §3]

7 "Esse prazer para o qual Sêneca emprega em geral os termos gaudium ou laetitia é um estado que não é acompanhado nem seguido por nenhuma perturbação no corpo e na alma; ele é definido pelo fato de não ser provocado por nada que seja independente de nós e que, por conseguinte, escapa ao nosso poder; ele nasce de nós e em nós mesmos. Ele é igualmente caracterizado pelo fato de que não conhece gradação nem mudança, mas que é dado 'por inteiro', e uma vez dado, nenhum acontecimento exterior pode atingi-lo. E nisso, essa espécie de prazer pode opor-se, traço por traço, ao que é designado pelo termo de voluptas; este designa um prazer cuja origem deve ser colocada fora de nós e nos objetos cuja presença não nos é assegurada." (Foucault, A História da Sexualidade 3, 71)

8 Na obra $O$ que é Filosofia antiga?, na seção dedicada a Plotino e Porfírio, Pierre Hadot cita uma passagem das Eneades [VI, 7.34], na qual Plotino distingue entre o prazer e a alegria: “"(...) quando a alma não tem mais consciência de seu corpo, nem que se encontra neste corpo e ela não diz mais que é diferente Dele: homem ou animal ou ser ou tudo (pois olhar as coisas é, de alguma maneira, fazer diferenças, e, por outro lado, ela não tem prazer em voltar-se para elas nem em desejá-las; mas, depois de tê-Lo buscado, quando Ele está presente, vai a Seu encontro e é para Ele que ela olha em vez de para si mesma, e ela não tem prazer em ver quem é, ela que olha) porquanto certamente ela não trocaria nenhuma de todas as outras coisas por Ele, mesmo se lhe fosse dado o céu inteiro, pois sabe que nada há de mais precioso e melhor que Ele [...] (pois lá engano nenhum é possível: encontrar-se-á onde mais verdadeiramente o verdadeiro? E o que ela diz, portanto: 'É Ele!', é mais tarde que o pronuncia, agora é seu silêncio que o diz, e, plena de alegria (eupathoûsa), não se engana, precisamente porque plena de alegria (eupathê̂); e nada diz, não por causa do prazer (gargalizoménou) que lhe acomete o corpo, mas porque ela se transformou naquilo que era outrora quando era feliz) [...] Se acontecesse que todas as coisas ao seu redor fossem destruídas, seria isso mesmo o que ela haveria de querer, contanto somente que estivesse com Ele: tão grande é a alegria (eupatheías) que ela alcançou".' [Pierre Hadot, O que é Filosofia antiga?, trad. de Dion Davi Macedo (São Paulo: Edições Loyola, 2011), 232-233]

9 "Os filósofos que especularam sobre o significado da vida e sobre o destino do homem não observaram bem que a própria natureza se deu ao trabalho de informar-nos sobre isso: avisa-nos por meio de um sinal preciso que nossa destinação foi alcançada. Esse sinal é a alegria. Estou falando da alegria, não do prazer. O prazer não passa de um artifício imaginado pela natureza para obter do ser vivo a conservação da vida; não indica a direção em que a vida é lançada. Mas a alegria sempre anuncia que a vida venceu, que ganhou terreno, que conquistou uma vitória: toda grande alegria tem um toque triunfal. Ora, se levarmos em conta essa indicação e seguirmos essa nova linha de fatos, veremos que em toda parte há alegria, há criação: quanto mais rica é a criação, mais profunda é a alegria. A mãe que contempla seu filho, alegra-se, porque tem consciência de havê-lo criado, física e moralmente. Acaso o comerciante que desenvolve seus negócios, o fabricante que vê sua indústria prosperar, alegra-se por causa do dinheiro que ganha e da notoriedade que adquire? Evidentemente riqueza e consideração contam muito na satisfação que sente, porém lhe trazem mais prazeres do que alegria; a alegria verdadeira que ele desfruta é o sentimento de ter montado uma empresa que funciona, de ter dado a vida a algo. Pensem nas alegrias excepcionais, a do artista que realizou seu pensamento, a do cientista que descobriu ou inventou. Ouvirão dizer que esses homens trabalham pela glória e obtêm suas alegrias mais vivas da admiração que inspiram. Profundo 
erro! O homem dá importância aos elogios e às honrarias na exata medida em que não está seguro de ter obtido êxito. No fundo da vaidade há modéstia. É para tranquilizar-se que ele busca aprovação, e é para sustentar a vitalidade talvez insuficiente de sua obra que gostaria de cercá-la da calorosa admiração dos homens, como se coloca em estufa uma criança nascida prematuramente. Mas quem estiver seguro, absolutamente seguro de que produziu uma obra viável e duradoura, esse não tem mais o que fazer do elogio e sente-se acima da glória, porque é criador, porque sabe disso e porque a alegria que sente é uma alegria divina. Portanto, se em todos os âmbitos o triunfo da vida é a criação, não devemos supor que a vida humana tem sua razão de ser em uma criação que, diferentemente daquela do artista e do cientista, pode prosseguir a todo momento em todos os homens: a criação de si por si, o engrandecimento da personalidade por um esforço que extrai muito do pouco, alguma coisa do nada e aumenta incessantemente a riqueza que havia no mundo?" [Henri Bergson, A energia espiritual, trad. de Rosemary Costhek Abílio (São Paulo: Martins Fontes, 2009), 22-23]

10 Acerca da influência histórico-filosófica de Kant sobre Pierre Hadot: Cf. Hadot, Exercices Spirituels, 374; Hadot, Exercices Spirituels, 389; Pierre Hadot, "De Socrate à Foucault", in: Philosophie comme manière de vivre, (Paris: Albin Michel, 2001), 217; Pierre Hadot, "La Philosophie comme éducation des adultes", in: La voix et la vertu : variétés du perfectionisme moral,org. por Sandra Laugier (Paris : Presses Universitaires de France, 2010), 439-447.

11 Para os estoicos, os animais são providos de impulsos perceptivos, os quais concernem à alma irracional. Os homens são providos de impulsos racionais, os quais nada mais são do que julgamentos práticos. Sendo assim, os homens que não aperfeiçoam a alma racional agem de acordo com impulsos que prescrevem o bem e o mal moral a coisas que, por si mesmas, são indiferentes, isto é, nem boas e nem más. Estes impulsos racionais estultos consistem nas paixões ou maus sentimentos (pátheia). O filósofo, aquele que se engaja no desenvolvimento da alma, deixa de ter paixões ou maus sentimentos e passa a ter impulsos racionais que estão de acordo com a natureza, nesse sentido, bons sentimentos (eupátheia). O prazer - quando decorre da crença de que algo indiferente por natureza, como a riqueza, é bom em si mesmo - é superficial e inconstante, ou seja, logo conduz à frustração ou ao tédio. No entanto, a alegria - que se segue da apropriada atribuição do bem à virtude moral - diz respeito a uma satisfação profunda e constante, ou seja, ela é a boa versão do prazer. Além disso, é provável que a diferença entre prazer (hèdonè) e alegria (khára) remonte à primeira fase do estoicismo, desenvolvida por Zenão e Crisipo, persistindo na segunda fase, a era de Panécio e Posidônio, e na terceira fase, representada pelos estoicos romanos, Sêneca, Musonio Rufus, Epicteto, Hierocles e Marco Aurélio. [Ted Brennan, "Psicologia moral estoica", in: Os Estoicos, trad. de Paulo Fernando Tadeu Ferreira e Raul Fiker (São Paulo: Odysseus, 2006), 299]

12 "Peço-te, Lucílio amigo, age da única maneira possível para obteres a felicidade: repele e despreza aqueles bens que só brilham por fora, que dependem das promessas de fulano ou das benesses de cicrano. Faz do verdadeiro bem o teu alvo, busca a alegria dentro de ti. Que significa 'dentro de ti'? Significa que a felicidade se origina em ti mesmo, na melhor parte de ti mesmo.” (Séneca, Cartas, Carta 23, 85; Seneca, Annaei Senecae, Ep.23,§6)

13 "Se queres saber em que consiste e donde provém o verdadeiro bem, vou dizer-to: consiste na boa consciência, nos propósitos honestos, nas ações justas, no desprezo pelos bens fortuitos, no ritmo tranquilo e constante de uma vida que trilha um único caminho." (Séneca, Cartas, Carta 23, 86; Seneca, Annaei Senecae, Ep. 23,§7)

14 "És um animal racional. Qual é então o teu bem próprio? A perfeita razão." (Séneca, Cartas, Carta 124, 704; Seneca, Annaei Senecae, Ep.124, §23) 
15 "Na realidade a razão é comum aos deuses e aos homens; naqueles atingiu a perfeição, nestes é suscetível de a atingir." (Séneca, Cartas, Carta 92, 470; Seneca, Annaei Senecae, Ep.92,\$27)

16 “"A melhor parte de si’ é, portanto, finalmente, um eu [soi] transcendente'." (Loque e Oliveira, Exercícios Espirituais, 293)

17 "De fato, o exercício estoico visa a ultrapassar o eu [soi], a pensar e a agir em união com a razão universal.” (Loque e Oliveira, Exercícios Espirituais, 293)

18 Sobre a influência de Epicteto no estoicismo de Marco Aurélio, Pierre Hadot explica que "há um tema altamente estruturado que integra logo no início algo que, pareceria, Epicteto é o único na tradição estoica, além de Marco Aurélio, a distinguir: as três atividades ou operações da alma. Há o desejo em acumular aquilo que é bom, o impulso a agir e o julgamento acerca do valor das coisas." [Pierre Hadot, The Inner Citadel: The meditations of Marcus Aurelius, trad. de Michael Chase (Cambridge: Harvard University Press, 2001a), 83]

19 "Em todo lugar e continuamente depende de você aproveitar, em concordância com o divino, o acontecimento presente, conduzir-se de forma justa em relação aos homens presentes e dar atenção à impressão presente a fim de que algo incompreensível não se insinue a

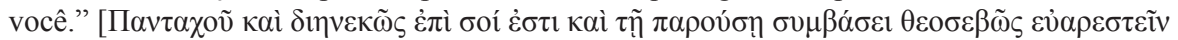

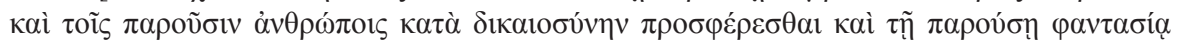

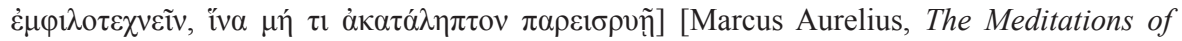
Marcus Aurelius, ed. bilíngue por C.R. Haines (Cambridge: Harvard University Press, 1930) Livro 7, §54, 186]

20 "Faz-se suficiente ter um julgamento compreensivo no presente, agir em virtude da comunidade no presente e ter disposição para aproveitar no presente o acontecimento cuja

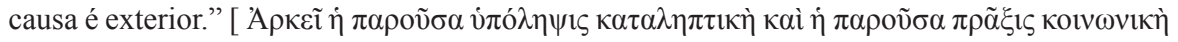

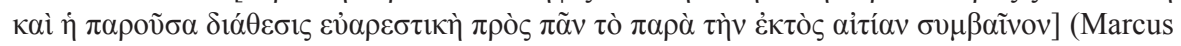
Aurelius, The Meditations, Livro 9, §6, 236)

21 "Toda natureza se satisfaz por si mesma, ao seguir seu caminho; a natureza racional segue seu caminho quando não assente a impressões falsas ou duvidosas, quando se orienta somente por impulsos que visam ao bem comum, quando se atém somente aos desejos e aversões que dependem de nós, acatando tudo o que a natureza comum nos atribui. Pois, nossa natureza é parte da natureza comum, assim como a natureza da folha é parte da

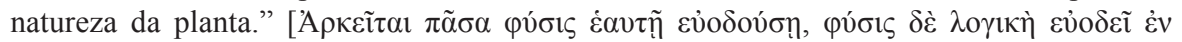

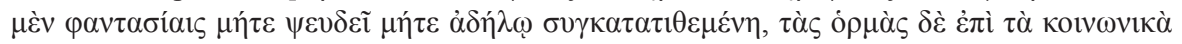

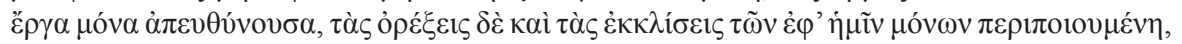

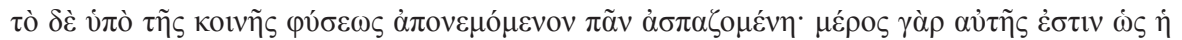

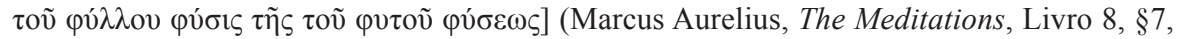
202)

22 "Para os estoicos, há apenas uma razão e essa razão é o verdadeiro eu [soi] do homem." (Loque e Oliveira, Exercícios Espirituais, 293)

23 "Uma alma que contempla a verdade, que atribui valor às coisas de acordo com a natureza e não com a opinião comum, que se insere na totalidade do universo (toti se inserens mundo) e observa contemplativamente todos os seus movimentos, que dá igual atenção ao pensamento e à acção, uma alma grande e enérgica, invicta por igual na desventura e na felicidade e em caso algum se submetendo à fortuna, uma alma situada acima de todas as contingências e eventualidades, uma alma bela e equilibrada em doçura e energia, uma alma sã, íntegra, imperturbável, intrépida, uma alma que força alguma pode vergar, que circunstância 
alguma pode envaidecer ou deprimir - uma tal alma é a própria personificação da virtude." (Séneca, Cartas, Carta 66, 238; Seneca, Annaei Senecae, Ep.66, §6)

24 "O sábio vive com consciência do mundo. O mundo está sempre presente perante ele. Esta consciência do mundo determina sua conduta na vida. [...] Esta consciência do mundo é uma coisa própria ao sábio. Somente o sábio não cessa de ter o todo constantemente presente no espírito, não esquece jamais do mundo, pensa e age em relação ao cosmos. Esta consciência dá a sua vida firmeza e constância ao mesmo tempo. Pelo contrário, o homem que não é um sábio não tem consciência do mundo e não atinge uma concepção universal das coisas e da sua própria vida. [...] O sábio faz parte do mundo, ele é cósmico. Ele não se deixa afastar do mundo, não se deixa desprender da engrenagem do mundo. [...] O sábio contempla o mundo e se sente unido a ele. As dissonâncias criadas pela paixão já não existem mais para ele. [...] Vive em conformidade com a norma do mundo e permanece na normalidade universal. [...] A consciência que ele tem de seu caráter e a que ele tem do mundo encontram, nesse caso, uma unidade última." [Bernard Groethuysen, Anthropologie Philosophique (Paris: Gallimard, 2012), 79, 80 e 81]

25 "Logo que a tua doutrina [a de Epicuro], obra de um gênio divino, começa a proclamar a natureza das coisas, dispersam-se os terrores do ânimo, apartam-se as muralhas do mundo, e vejo como tudo se faz pelo espaço inteiro. Aparece o poder divino e as mansões tranquilas que nem os ventos abalam, nem as nuvens regam com suas chuvas, nem a branca neve, reunida pelo frio agudo, profana, caindo, e que um límpido céu sempre protege e que sempre riem na luz largamente difundida. Tudo lhes fornece a natureza, nada lhes toca em tempo alguma paz da alma. E, pelo contrário, jamais aparecem as regiões do Aqueronte, e a Terra não impede que se veja tudo o que, sob nossos pés, sucede nos espaços vazios; perante tudo isto me toma divina volúpia e temeroso respeito (divina voluptas percipit atque horror), pelo fato de a natureza, descoberta pelo teu gênio, assim se ter manifestado abertamente em completa nudez." [Lucrécio, "Da Natureza", in : Os Pensadores V, trad. de Agostinho da Silva. (São Paulo: Abril Cultural, 1973), Livro III, 71; Lucreti, De Rerum Natura, ed. bilíngue por Cyril Bailey. (Oxford: Oxford University Press), 2001, Liber Tertius, §§15-30, 302]

26 EPICURO. "Antologia de textos", in: Os Pensadores $V$, trad. de Agostinho da Silva (São Paulo: Abril Cultural, 1973), 28.

27 A notável obra mencionada por Pierre Hadot, e abordada por Foucault no artigo "A

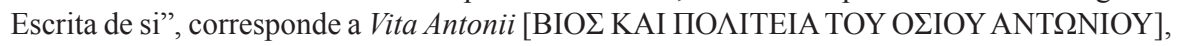
de Atanásio de Alexandria. Esta obra consiste em uma carta na qual Atanásio relata a vida do monge Antônio a outros discípulos que pretendem se dedicar ao celibato. De acordo com Pedro Ipiranga Júnior: "escrever a vida e a conduta de Antônio, o eremita, assinala como sua finalidade, a princípio, fornecer uma narrativa paradigmática aos correspondentes, os quais querem ter um modelo de que possam fazer mímesis em sua prática ascética." [Pedro Ipiranga Júnior, "Imagens do outro como um si mesmo: drama e narrativa nos relatos biográficos de Luciano de Samósata e na 'Vita Antonii' de Atanásio" (Tese de Doutorado em Literatura Comparada apresentada à Faculdade de Letras da Universidade Federal de Minas Gerais, 2006), 247]

28 "Quando se aborda os comentários de Aristóteles e Platão redigidos pelos neoplatônicos, tem-se, de início, a impressão de que a redação dos neoplatônicos é conduzida unicamente por preocupações doutrinais e exegéticas. Mas, por meio de um exame profundo, percebe-se que o método de exegese e seu conteúdo doutrinal correspondem, em cada comentário, a função de nível espiritual do público ao qual o comentário se direciona. (...) Isso não quer 
dizer que havia variação doutrinal de acordo com o comentador, mas que as necessidades dos discípulos eram diferentes." (Hadot, Exercices Spirituels, 69)

29 “"Mas, para assegurar o não pecar, que se tenha também esta vigilância: cada um,

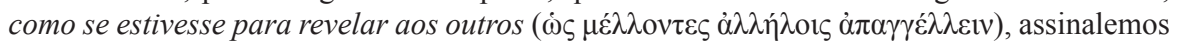
$(\sigma \eta \mu \varepsilon เ \omega ́ \mu \varepsilon \theta \alpha)$ as ações e os movimentos da alma e os grafemos ( $\gamma \rho \alpha ́ \varphi \omega \mu \varepsilon v)$. E estejais seguros de que, certamente, envergonhando-se de se tornarem tais coisas conhecidas, cessaremos de pecar e, de toda forma, de ter no espírito algo de vil. Pois quem, ao pecar, quer ser visto? Quem, tendo pecado, não mente de preferência, querendo passar despercebido? Assim como, então, vendo uns aos outros, não nos entregaríamos à fornicação, assim também, se nós escrevermos, como se revelássemos aos outros o que pensamos e imaginamos, muito bem nos guardaremos dos pensamentos sujos, envergonhando-nos de serem conhecidos." [Ipiranga Júnior, trad. Atanásio, Vitta Antonii, (Tese de Doutorado em Literatura Comparada apresentada à Faculdade de Letras da Universidade Federal de Minas Gerais, 2006), 262; Athanasios, Bios kaì Politeía Antoníou Tou Megálou (Thessalonike: Ekdotikòs Oíkos Bas. Regopoúlou, 2000), §55, 112]

30 "Por mais pessoais que sejam, esses hypomnèmata não devem, entretanto, ser compreendidos como diários íntimos, ou como aquelas narrativas de experiência espiritual (tentações, lutas, derrotas e vitórias) que podem ser encontradas na literatura do cristianismo tardio. Eles não constituem uma 'narrativa de si mesmo'; eles não têm por objetivo trazer à luz do dia os arcana conscientiae cuja confissão - oral ou escrita - tem valor purificador. O movimento que eles procuram efetuar é inverso a esse: não se trata de possuir o indizível, nem de revelar o indizível, nem de dizer o não dito, mas de captar, ao contrário, o já- dito; resumir o que se pôde ouvir ou ler, isso por um fim que nada mais é do que a constituição de si." [Michel Foucault, Dits et Écrits II. 1976-1988 (Paris: Gallimard, 2001), 1238]

31 Focault, Dits et Écrits II, 1239.

32 Foucault, Dits et Écrits II, 1240.

33 No artigo publicado em 1986, na revista Diogène, Hadot pretende explorar a antiga experiência do tempo que se exprime no Fausto de Goethe. De acordo com Hadot, Fausto faz eco aos seguintes motes: “'Somente o presente é nossa felicidade' e 'Existir é um dever'. Goethe falou em suas Entretiens avec Falk de certos seres que, por suas tendências inatas, são metade estoicos e metade epicuristas (...). Pode-se dizer que o próprio Goethe, no que concerne à maneira de viver o presente, era ele também 'metade estoico e metade epicurista'. Ele desfrutava do momento presente como um epicurista e ele o desejava intensamente como um estoico." (Pierre Hadot, "Le Présent seul est notre bonheur", Diogène (1986), n¹33,75)

34 "No entanto, embora permita contrariar a dispersão da stultitia, a escrita dos hypomnèmata é também (e assim deve permanecer) uma prática regrada e voluntária da disparidade. Ela é uma escolha de elementos heterogêneos." (Foucault, Dits et Écrits II, 1240)

35 Foucault, Dits et Écrtis II, 1240.

36 Edson Passetti, em sua obra Ética dos Amigos: invenções libertárias da vida, cita Alicia Páez acerca do ecletismo filosófico no período romano: "Páez afirma que 'a filosofia romana foi muito eclética: os romanos não aderiram a uma doutrina, tendiam a misturar fronteiras, a assimilar as diferenças. Não adotavam uma filosofia em sua totalidade, nem tampouco se interessavam pela coerência dos sistemas. O ecletismo característico da filosofia romana conformada desde os fins da república (todas as escolas da antigüidade, as socráticas maiores e menores, estavam representadas em Roma) responderia, segundo alguns intérpretes, ao caráter fundamentalmente prático desta filosofia: falta de espírito especulativo, interesse pelas 
questões cosmológicas, físicas, lógicas com o predomínio do interesse pelos motores da ação. Se falamos de ética e práticas sociais no caso dos estóicos, temos de assinalar que mesmo sendo a escola dominante no mundo romano-imperial, trata-se de um estoicismo modificado em relação ao antigo: pode-se dizer que é um estoicismo eclético. Sêneca, por exemplo, manifesta a influência de diversos autores, e por vezes parece admirar mais a Epicuro que os próprios estóicos gregos'." [Edson Passetti, Éticas dos Amigos: invenções libertárias da vida (São Paulo: Imaginário, 2003), 51]

37 "A Academia, com os sucessores de Arquesilau, Carneada e Fílon de Larissa, evoluiu na direção do probabilismo. (...) Essa tendência filosófica teve grande influência sobre a filosofia moderna graças ao imenso sucesso, no Renascimento e nos tempos modernos, das obras filosóficas de Cícero. Põe-se em obra essa filosofia acadêmica que dá ao indivíduo a liberdade de escolher, em cada caso concreto, a atitude que ele julgue a melhor conforme as circunstâncias, mesmo que inspirada pelo estoicismo ou pelo epicurismo ou outra filosofia, sem impor-lhe a priori uma conduta a seguir, ditada por princípios anteriormente fixados." (Hadot, $O$ que é a Filosofia antiga?, p.207) Em Cícero encontramos a seguinte explicação sobre os acadêmicos: "os Acadêmicos sustentam que existem diferenças entre coisas desse tipo tal que algumas coisas parecem prováveis (probabilis) e outras o oposto." (Cícero, "Academica 2.103-4", in: The Hellenistic Philosophers: greek and latin texts with notes and bibliography, ed. bilíngue por de A. A. Long e D.N Sedley (Cambridge: Cambridge University Press, 2009. 2v), 69I] O adjetivo "probabilis", utilizado por Cícero, traduz o termo grego "pithanós", o qual é bastante recorrente nas explicações de Diógenes Laércio acerca de Aristóteles e do estoicismo. $\mathrm{O}$ adjetivo "pithanós" significa provável, plausível, crível ou persuasivo.

38 “....) a escrita transforma a coisa vista ou ouvida 'em forças e sangue' (in vires, in sanguinem). Ela se faz, no próprio escritor, um princípio de ação racional. Mas, inversamente, o escritor constitui sua própria identidade através dessa recolecção das coisas ditas." (Foucault, Dits et Écrits II, 1241)

39 "não somente não se escreve si mesmo, como a escrita não constitui o eu [soi]." (Loque e Oliveira, Exercícios Espirituais, 297)

40 "Foucault centrou, sobretudo, sua ideia das práticas de si em uma certa atitude do indivíduo, que ele chamou de estética da existência e que consiste, definitivamente, em fazer com que sua existência seja bela. [...] Ao contrário, eu teria, sobretudo, tendência a ser menos inteiramente 'ético' e mais sensível a noção que eu estudei através da Antiguidade, desde o Timeu até o fim da Antiguidade, da física como exercício espiritual. Eu estou mais interessado no aspecto cósmico da filosofia - talvez em virtude das experiências particulares que eu havia tido, como aquela de um 'sentimento oceânico'." (HADOT, 1993, p.390-391, tradução nossa) Acerca da experiência do "sentimento oceânico", Hadot relata: "eu fui invadido por uma angústia ao mesmo tempo terrificante e deliciosa, provocada pelo sentimento da presença do mundo, ou do Todo, e de mim nesse mundo. [...] Bem mais tarde, eu viria a descobrir que essa tomada de consciência de minha imersão no mundo, essa impressão de pertença ao Todo, corresponderia a isso que Romain Rolland chamou de 'sentimento oceânico'." (Hadot, La Philosophie, 23-24)

41 “(...) a interiorização é superação de si [dépassement de soi] e universalização.” (Loque e Oliveira, Exercícios Espirituais, 298) Com efeito, o substantivo "dépassement" pode ser traduzido por "superação". Entretanto, decidimos traduzir a expressão "dépassement de soi" por "ultrapassagem de si" porque, desse modo, harmonizamos o substantivo "dépassement" com o verbo do qual ele é derivado, a saber, "dépasser", traduzido em nossa versão por "ultra- 
passar". Além disso, sabe-se que a noção "dépassement de soi" é extremamente relevante para a filosofia de Pierre Hadot, já que através dela Hadot interpreta a característica mais importante dos antigos exercícios espirituais, ou seja, a grandeza d'alma [megalopsuchia], prática que se vincula ao exercício da morte, o qual permite que a essencialidade da identificação entre o logos humano e o logos divino seja desvelada. (Hadot, Exercices Spirituels, 53-54) Concebemos, sendo assim, que o substantivo "ultrapassagem" é mais interessante para o contexto dos estudos de Pierre Hadot e também para o desenvolvimento do seu diálogo com Michel Foucault. A partir do conceito de "ultrapassagem", torna-se possível visualizar a platônica relação entre o corpo e a alma no contexto da dedicação filosófica. Nesse caso, a ultrapassagem é psíquica e, diferentemente do que o termo "superação" poderia denotar, diz respeito a um árduo movimento da alma que se desenrola agonicamente. Os entraves entre o corpo e a alma no platonismo não concernem simplesmente a uma superação moral, mas também a uma mudança de estado físico e psíquico em vista do utópico deslocamento para um outro mundo. [Fréderic Gros, "Situação do Curso", in: Michel Foucault, A Coragem da Verdade, trad. de Eduardo Brandão, (São Paulo: Martins Fontes, 2011a), 314-315] Nesse sentido, o prefixo "ultra" denotaria o movimento de transcendência que conduz à descoberta da natureza humana, tal como Hadot pretende significar a partir da expressão "dépassement de soi”. Ademais, talvez seja possível contrapor a concepção de Hadot acerca do "dépassement de soi" à forma pela qual Foucault concebe a atitude filosófica (êthos filosófico). De acordo com Michel Foucault, o êthos filosófico concerne a uma atitude limite capaz de desencadear o questionamento sobre os limites do saber, do poder e das estruturas do sujeito: "se a questão kantiana era a de saber quais limites o conhecimento deve renunciar a transgredir [franchir], parece-me que a questão crítica hodiernamente deve ser transformada em questão positiva: nisso que nos é dado como universal, necessário, obrigatório, qual é a parte disto que é singular, contingente e relativa a restrições arbitrárias. Em suma, trata-se de transformar a crítica exercida na forma da limitação necessária em uma crítica prática exercida na forma da transgressão possível [franchissement possible]." (FOUCAULT, Dits et Écrits II, 1393) De modo geral, poderíamos afirmar que a transgressão possivel se opõe a ultrapassagem de si, na medida em que consiste em um movimento imanente que não busca a dimensão utópica de um outro mundo, mas sim a transformação deste mundo e desta vida em algo novo, inusitado e, até então, impossível. O prefixo "trans", diferentemente do prefixo "ultra", expressaria o movimento imanente e heterotópico da vida daquele que pretende se relacionar criativamente com este mundo.

42 Philippe Chevallier explica que Foucault se refere ao dandismo em dois momentos importantes, a saber, no curso A Hermenêutica do Sujeito [Michel Foucault, A Hermenêutica do Sujeito, 13 e 224] e no artigo O que são as Luzes? (Foucault, Dits et Écrits II, 1387-1388). Ademais, seria imprescindível acrescentar, para além dos textos apontados por Chevallier, a referência que Foucault empreende a Baudelaire no curso $A$ Coragem da Verdade, dedicado ao movimento cínico (Foucault, $A$ Coragem da Verdade, 165). De acordo com Chevallier, é no artigo $O$ que são as Luzes? "que pensa o historiador Pierre Hadot quando critica a estética da existência foucaultiana, que confundiria o cuidado de si antigo com uma nova forma de 'dandismo'. [...] Hadot sentiu bem que havia aí um ponto crítico na obra de seu colega e amigo. O imbricamento dos temas dos quais Baudelaire é aqui a ocasião se revela efetivamente tão fascinante quanto perturbadora. [...] Este imbricamento de períodos e referências faz juntar audaciosamente a Antiguidade e a modernidade. Algo dura, perdura em certa atitude diante de si e diante do presente do qual Foucault traça repetidamente genealogias rápidas, através de seus cursos, artigos e entrevistas dos últimos anos: de Sêneca a Montaigne e Descartes (para 
a filosofia como exercício espiritual); depois para Kant, Hegel e Nietzsche (para o cuidado do presente); e enfim Stirner, Baudelaire, Schopenhauer (para o cuidado de si). Genealogias hesitantes, entretanto, pois a história foucaultiana marca no mesmo movimento as rupturas e as difíceis retomadas." (Philippe Chevallier, "O Baudelaire de Foucault: uma silhueta furtiva e paradoxal”, Anuário de Literatura da UFSC (2013), trad. de Pedro de Souza, v.18, n.1, 194 e 195)

43 “A questão de se estamos contentes conosco não é absolutamente a primeira, mas sim a de se estamos contentes com alguma coisa em geral. Se dissermos sim em um único instante, então teremos dito sim não só a nós mesmos, mas à existência como um todo. Pois nada se sustenta por si, nem em nós mesmos, nem nas coisas: e se só por uma única vez nossa alma vibrou e soou de felicidade como uma corda de um instrumento, então todas as eternidades foram necessárias para condicionar esse único acontecer - e toda eternidade foi abençoada, libertada, justificada e assentida nesse único momento do nosso dizer sim." [Friedrich Nietzsche, $A$ Vontade de Poder, trad. de Marcos Sinésio Pereira Fernandes e Francisco José Dias de Moraes (Rio de Janeiro: Contraponto, 2011) §1032, 496]

44 “(...) somente ao animal racional é dada a possibilidade de se conformar volunta-

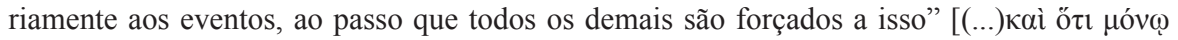

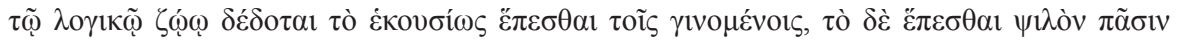

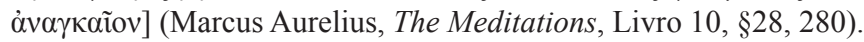

\section{Bibliografia utilizada na tradução}

ATHANASIOS, O Megas. Bios kaì Politeía Antoníou Tou Megálou. IN: O MEGAS ANTONIOS. Bios kaì Politeía upò M. Athanasiou, Diegéseis, Apophthégmata kaì Epistolaì ek diaphorôn asketikôn Syllógon, Parainéseis es tês Philokalías ton Ierôn Neptikôn. Metéphrasis, Skhólia kaì Paraterései upò Theo. D. Sakelaríou. Thessalonike: Ekdotikòs Oíkos Bas. Regopoúlou, 2000.

BERGSON, Henri. A energia espiritual. Tradução de Rosemary Costhek Abílio. São Paulo: Martins Fontes, 2009.

BRENNAN, Ted. "Psicologia moral estoica", in: Os Estoicos, trad. de Paulo Fernando Tadeu Ferreira e Raul Fiker. São Paulo: Odysseus, 2006, 285-327.

CHEVALLIER, Philippe. "O Baudelaire de Foucault: uma silhueta furtiva e paradoxal", Anuário de Literatura da UFSC (2013), Florianópolis, trad. de Pedro de Souza, v.18, n.1,190-197.

DAVIDSON, Arnold I. "Ethics as Ascetics: Foucault, the History of Ethics, and Ancient Thought", in: The Cambridge Companion to Foucault, ed. por Gary Gutting. Cambridge: Cambridge University Press, 2006,123-149.

EPICURO. "Antologia de textos", in: Os Pensadores $V$, trad. de Agostinho da Silva. São Paulo: Abril Cultural, 1973.

FOUCAULT, Michel. A Hermenêutica do Sujeito, trad. de Márcio Alves da Fonseca e Salma Tannus Muchail. São Paulo: Martins Fontes, 2010.

FOUCAULT, Michel. A História da Sexualidade 2: O uso dos prazeres, trad. de Maria Thereza da Costa Albuquerque. São Paulo: Graal, 2012.

FOUCAULT, Michel. A História da Sexualidade 3: O cuidado de si, trad. de Maria Thereza da Costa Albuquerque. São Paulo: Graal, 2011. 
FOUCAULT, Michel. A Coragem da Verdade, trad. de Eduardo Brandão. São Paulo: Martins Fontes, 2011a.

FOUCAULT, Michel. Dits et écrits II. 1976-1988. Paris: Gallimard, 2001.

GROETHUYSEN, Bernard. Anthropologie Philosophique. Paris: Gallimard, 2012.

HADOT, Pierre. "Le Présent seul est notre bonheur", Diogène (1986), Paris, nº133, 58-81.

HADOT, Pierre. Exercices Spirituels et philosophie antique. Paris: Albin Michel, 1993.

HADOT, Pierre. Exercícios Espirituais e Filosofia Antiga, trad. de Flavio Fontenelle Loque e Loraine Oliveira. São Paulo: É Realizações, 2014.

HADOT, Pierre. O que é a Filosofia antiga?, trad. de Dion Davi Macedo. São Paulo: Edições Loyola, 2011.

HADOT, Pierre. "La Philosophie comme éducation des adultes", in: La voix et la vertu: Variétés du perfectionnisme moral, org. por Sandra Laugier. Paris : Presses Universitaires de France, 2010, 439-447.

HADOT, Pierre. La Philosophie comme manière de vivre: entretiens avec Jeannie Carlier et Arnold I. Davidson. Paris: Albin Michel, 2001.

HADOT, Pierre. The Inner Citadel: The meditations of Marcus Aurelius, trad. de Michael Chase. Cambridge: Harvard University Press, 2001a.

IPIRANGA JÚNIOR, Pedro. Imagens do outro como um si mesmo: drama e narrativa nos relatos biográficos de Luciano de Samósata e na "Vita Antonii" de Atanásio. 321 f. (Tese Doutorado em Literatura Comparada). Faculdade de Letras da Universidade Federal de Minas Gerais, Belo Horizonte. 2006.

LONG, A.A e SEDLEY, D.N. The Hellenistic Philosophers: Greek and Latin texts with notes and bibliography. Cambridge: Cambridge University Press, 2009. 2v.

LUCRÉCIO. "Da Natureza", in: Os Pensadores $V$, trad. de Agostinho da Silva. São Paulo: Abril Cultural, 1973.

LVCRETVI. De Rerum Natura, ed. bilíngue por Cyril Bailey. Oxford: Oxford University Press, 2001.

MARC-AURÈLE. "Pensées", in: Les Stö̈ciens II, trad. de Émile Bréhier. Paris: Gallimard, 1962.

MARCO AURÉLIO. "Meditações", in: Os Pensadores, trad. de Jaime Bruna. São Paulo: Cultrix, 1973.

MARCVS AURELIVS. The Meditations of Marcus Aurelius, ed. bilíngue por C.R. Haines. Cambridge: Harvard University Press, 1930.

NIETZSCHE, Friedrich. A vontade de poder, trad. de Marcos Sinésio Pereira Fernandes e Francisco José Dias de Moraes. Rio de Janeiro: Contraponto, 2011.

PASSETTI, Edson. Éticas dos Amigos: invenções libertárias da vida. São Paulo: Imaginário, 2003.

SÉNECA. Cartas a Lucílio, trad. de J.A. Segurado e Campos. Lisboa: Calouste Gulbenkian, 2004.

SENECA. L. Annaei Senecae ad Lucilium Epistulae Morales, ed. por L.D. Reynolds. Oxford: Oxford University Press, 1965.

VERNANT, Jean-Pierre. "L'individu dans la cité", in: L'individu, la mort, l'amour: soi-même et l'autre en Grèce ancienne. Paris: Gallimard, 2011. 
(Página deixada propositadamente em branco.) 